\title{
Benvenuto Samson zum Gruße
}

Neunzig Jahre alt zu werden, ist eine Gnade des Lebens. Wir denken dabei an das bekannte Bibelwort. Wenn sich aber in der Person dessen, der auf neun Jahrzehnte seines Lebens zurückblicken kann, zusammen mit den Erfahrungen eines langen Lebens ungebrochene Aktivitäten und Interessen wie bei Benvenuto Samson verbinden und sich auf die Ebene des Wissenschaftlichen in so hervorragendem Maße projizieren, ist dies ein Phänomen.

Man betrachte sein Bild, das diesem Band vorangestellt ist. Man wird den Eindrudk haben, es ist das Bild eines vielleicht Endfünfzigers. Hier bewahrheitet sich, daß der Geist des unaufhörlichen Trainings bedarf, um den durch Arbeit und Erfolg erreichten Höhepunkt zu halten. Benvenuto Samson hat mit seinen Leistungen auch der jüngsten Zeit nicht nur den schon zuvor erreichten Höhepunkt gehalten, sondern ihn noch erheblich aufgestockt.

Das Impressum seines "kommentierenden Lehrbuchs" zum Urheberrecht verzeichnet das Jahr 1973. Mit diesem Buch hat der Verfasser ein Lebensbekenntnis zum Urheberrecht abgelegt. Seine zwischenzeitlich erschienenen Beiträge bestätigen aufs neue die Vielfalt seiner Interessen und den wissenschaftlichen Rang in der Behandlung der von ihm in Aufsätzen und Schrifttumsbesprechungen aufgegriffenen Themen. Auch wo Urheberrecht von ihm behandelt wird, geschieht dies aus einer umfassenden Kenntnis des allgemeinen Rechts und der gesellschaftlichen Fakten. Er hielt Schritt mit der Entwicklung der Technik, und er vertiefte seine Betrachtungen gelegentlich durch rechtsphilosophische Erkenntnisse. So stehen in den Jahren zwischen der Vollendung seines 85 . und seines 90. Lebensjahres Leistungen, die ihn mit den Rechtssystemen des Urheberrechts und der verwandten Schutzrechte ebenso verbinden wie mit den Problemen der Computerkunst und der Topik.

Die UFITA weiß sich glücklich, wenn sie mit dem vorliegenden Band, der in enger Zusammenarbeit mit Dr. Ernst Windisch, Richter am Bundesgerichtshof, und Dr. Hans-Heinrich Schmieder, Richter am Bundespatentgericht, entstanden ist, dem Rechtsanwalt und 
Honorarprofessor Benvenuto Samson zu seinem Geburtstag am 11. Juni 1977 eine Ehrengabe mit 25 Beiträgen von Kollegen, Freunden und Schülern überreicht. Diese Beiträge sind in Kenntnis seiner Persönlichkeit und seines wissenschaftlichen Schaffens für ihn niedergelegt worden. Jeder der Beitragsverfasser übermittelt in dieser Weise und die UFITA insgesamt dem Jubilar mit dem Ausdruck des Dankes die allerbesten Wünsche für sein Wohlergehen und sein weiteres Schaffen.

Georg Roeber 